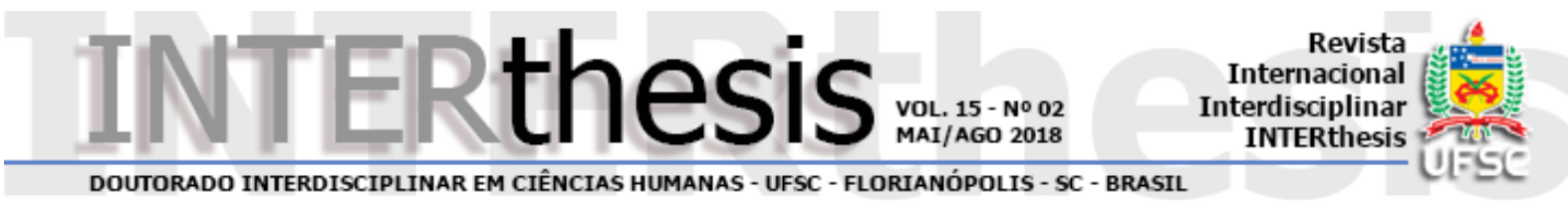

\title{
ORGANISMOS GENETICAMENTE MODIFICADOS: A LEGALIZAÇÃO NO BRASIL E O DESENVOLVIMENTO SUSTENTÁVEL
}

\section{Resumo:}

Alessandra Alvissus de Melo Salles Ultchak ${ }^{1}$

Análise da legalização dos alimentos transgênicos no Brasil diante dos riscos e mecanismos de controle em relação à produção e comercialização dos Organismos Geneticamente Modificados (OGMs). Para tanto, realizou-se revisão bibliográfica. A Lei de Biossegurança $n^{\circ} 11.105$ de 24 de março de 2005, legalizou a produção de OGMs no Brasil, inicialmente autorizando o plantio da soja geneticamente modificada; desde então, a norma vem sendo adaptada à necessidade de segurança da saúde humana e do meio ambiente. Serão abordadas as deficiências das pesquisas científicas para apuração da segurança do meio ambiente e dos consumidores, assim como a receptividade destes alimentos geneticamente modificados no mercado. Como o Estado Democrático de Direito é responsável pela tutela do meio ambiente e saúde dos seres humanos, será analisado o caminho percorrido sob a óptica da Bioética e do Biodireito. Em suma, discute-se problemas referentes a insuficiência de pesquisas científicas quanto a produção de OGMs e segurança alimentar, os riscos de exposição do meio ambiente e do homem a um dano irreversível, a necessidade econômica e tutela do Estado em observância ao desenvolvimento sustentável.

Palavras-chave: Transgênicos. Biossegurança. OGMs. Desenvolvimento. Sustentável.

\section{INTRODUÇÃO}

Com a descoberta do ADN/DNA em 1944 pelo médico norte-americano Oswald Theodore Avery, foi possível que outros estudiosos descobrissem o código genético, possibilitando a manipulação dos genes (RODRIGUES, 2003, p.102) e, consequentemente, a estrutura genética de organismos vivos, alterando algumas espécies e criando novas, como é o caso dos transgênicos.

Os Organismos Geneticamente Modificados (OGMs) são popularmente conhecidos como transgênicos. No entanto, existe uma diferença semântica. Alguns autores consideram transgênico todo organismo cujo material genético sofreu alteração em sua estrutura, a partir da técnica do DNA recombinante, com a

\footnotetext{
${ }^{1}$ Mestre em Ciências Ambientais pela Universidade de Taubaté. Auxiliar docente do Departamento de Ciências Jurídicas na Universidade de Taubaté, Taubaté, SP, Brasil E-mail: alealvissus@yahoo.com.br
} 
introdução de fragmentos genéticos de um organismo de espécie diferente da espécie destinatária. Nesta linha de pensamento, os OGMs podem ser transgênicos ou não, dependendo do fator de em seu genoma ser introduzido material genético proveniente de espécie diferente ou da mesma (GUERRANTE, 2003, p. 4). Entretanto, a maioria dos estudiosos usam os termos OGMs e transgênicos como sinônimos.

A cultura comercial de alimentos transgênicos no mundo iniciou-se em 1996. Em 1998 foi introduzido no Brasil o plantio comercial de soja geneticamente modificada Roundup através de licença concedida pela CTNBio para empresa Monsanto. Com o advento da Lei 11.105 de março de 2005 - Lei de Biossegurança, os Organismos Geneticamente Modificados foram legalizados no Brasil e, inicialmente, somente a soja geneticamente modificada tolerante a glifosato, registrada no Registro Nacional de Cultivares do Ministério da Agricultura, Pecuária e Abastecimento, tinha autorização para produção e comercialização.

A legalização de alimentos transgênicos no Brasil trouxe polêmica na imprensa e nas organizações ambientais. Desde então, muitas discussões vem sendo travadas quanto a inseguranças na produção de OGMs, fator este dilatou a concessão de licenças para plantio em escala comercial.

A Lei de Biossegurança refere-se somente a nomenclatura de OGM, definindo este como: "organismo cujo material genético - ADN/ARN tenha sido modificado por qualquer técnica de engenharia genética" e organismo é definido como: "toda entidade biológica capaz de reproduzir ou transferir material genético, inclusive vírus e outras classes que venham a ser conhecidas" (BRASIL, 2005).

Um risco bastante preocupante em relação ao consumo de OGMs está relacionado a reações adversas dos alimentos e seus derivados. De acordo com o efeito, estes produtos podem ser classificados em alergênicos, que causam sensibilidades alérgicas ou intolerantes, responsáveis por alterações fisiológicas como reações metabólicas anormais e toxidade (FINARDI, 1999 apud NODARI; GUERRA, 2003, p. 108).

Outra preocupação que norteia a temática está na insuficiência de pesquisas referentes aos riscos de produção de OGMs em relação ao meio ambiente, destacando-se a poluição genética, surgimento der superpragas e danos a espécies circundantes, os quais poderiam ser irreversíveis e o comprometer o desenvolvimento sustentável. 
O principal ponto de discussão em relação às ciências biotecnológicas, sob a óptica da Bioética e do Biodireito, está pautado em quais os limites devem ser impostos para o desenvolvimento desenfreado na área? A quem caberia à ponderação de riscos e medidas preventivas? A CTNBIO certamente não exerce este perfil e nem o governo federal quer assumir este papel de paralisação, afinal, o agronegócio existente no país sustenta o superávit comercial, colocando a segurança socioambiental em segundo plano.

O que se denota é que cabe à comunidade científica dirimir as controvérsias a respeito dos OGMs, atuando de forma independente, sem perfilar por trás de grupo e de comissão, como se eles fossem os únicos arautos da razão (LEITE, 2007, p 47).

\section{ORGANISMOS GENETICAMENTE MODIFICADOS (OGMS): REFLEXOS AO MEIO AMBIENTE, CONSUMIDORES E AGRONEGÓCIO}

A engenharia genética consiste num conjunto de técnicas que visam transferir genes de uma espécie para outra, alterando-se assim, estrutura genética desta (GUERRANTE, 2003, p.4). Entretanto, o resultado desta intervenção humana na codificação genética dos seres vivos é algo cujas consequências são desconhecidas, fator que torna discutível a temática em questão, referente à legalização de transgênicos para produção comercial e consumo humano.

Alguns riscos em relação à produção e consumo de OGMs já foram estudados, porém, é notória a insuficiência de pesquisas sobre o assunto.

Existem duas frentes de pesquisas alusivas aos riscos dos transgênicos: a saúde humana e o meio ambiente. A primeira decorre do raciocínio de que plantas geneticamente modificadas venham secretar substâncias incomuns ou inexistentes em alimentos convencionais, as quais serão ingeridas e, em consequência da transgenia, podem acarretar processos alérgicos e disfunções fisiológicas, desencadeando novas doenças (KREUZER; MASSEY, 2000). Estudos científicos apontam que não há riscos identificáveis para saúde dos consumidores, em contrapartida, persiste o argumento de que o prazo de duração destes experimentos é insuficiente para identificação de efeitos danosos.

Em relação aos riscos para o meio ambiente, pode-se destacar: a) eliminação de espécies animais e microorganismos do ecossistema (LOSEY; RAYVOR; CARTER, 1999); b) contaminação de espécies convencionais (naturais) por troca de 
pólen com culturas transgênicas - hibridização; c) com a mudança genética das espécies, existe um risco potencial de geração de novos vírus que causem doenças, bactérias infecciosas, genes resistentes a certos antibióticos, geração de doenças decorrentes da manipulação genética, tanto para os vegetais como para os animais e o homem.

No tocante a saúde e meio ambiente, um importante experimento recentemente realizado no Brasil com o mosquito Aedes aegypti, inseto associado a dengue, febre amarela, febre chicungunya e zika vírus. Mosquitos machos geneticamente modificados (GM) carregam um gene inofensivo para os próprios insetos que os possuem, é letal para a prole, a qual que morre no estado larval, reduzindo a população do vetor (AZEVEDO, 2016). Esta experiência foi realizada em um bairro de Piracicaba (SP) e segundo o serviço de Vigilância Epidemiológica houve redução de $91 \%$ nos casos de dengue referente ao período de 2015/2016. O resto do município viu uma redução de $52 \%$ na incidência de dengue durante o mesmo período (ISAAA, 2016; OXITEC, 2016).

As implicações de cunho econômico também devem ser avaliadas, uma vez que o Brasil é um grande produtor agrícola e poderia comprometer seu mercado. Dentre estas, pode-se enfatizar algumas tecnologias utilizadas: a) tecnologia "Terminator" empregada para esterilidade das sementes, evitando-se a reprodução das plantas, uma forma desenvolvida para que os agricultores não guardem semente de uma safra para plantio em safra posterior, obrigando-os, assim, a comprarem sistematicamente as sementes das empresas detentoras da tecnologia de produção de sementes GMs; b) a tecnologia "Traitor" que consiste em condicionar a utilização de determinada substância química para ativar ou desativar determinadas características específicas das plantas, geradas pela manipulação genética como por exemplo: amadurecimento, sabor e qualidade nutricional, resistência à insetos e outras (GUERRANTE, 2003, p. 34), implicaria em maior dependência dos agricultores em relação às empresas produtoras, pois, além da obrigatoriedade de consumir as sementes, teria que adquirir as substâncias químicas de controle; c) a oligopolização do mercado de sementes, ou seja, a concentração em uma empresa da tecnologia da produção da semente GMs ao setores agroquímicos e farmacêutico; d) a perda de mercado - o Brasil é um dos grandes produtores agrícolas que exporta alimentos (GUERRANTE, 2003, p. 62). 
Das 20 maiores organizações com patentes sobre plantas ou sementes transgênicas, 05 estão ligadas a organizações européias, duas são empresas japonesas e 13 são norte-americanas. Destacam-se as empresas Dupont, SanofiAventis, Astrazeneca e Monsanto (AUGUSTO, 2015). Ressalta-se a existência de um protecionismo dos governos em favor de suas empresas em decorrência do faturamento daquelas, diretamente impactante nos PIBs dos países em que se situam suas matrizes, assim como em relação aos investimentos em pesquisa para de novas moléculas químicas a serem utilizadas em processos tecnológicos, especialmente na agricultura, os quais gerarão promissória riqueza.

Denota-se que o cultivo de transgênicos cresceu em desequilíbrio com a burocracia, ou seja, o desenvolvimento de documentos legais que o regulassem e a fiscalização não acompanharam a produção, comercialização e rotulagem para segurança do consumidor.

Desde 1996 mais de 10 culturas alimentares e de fibras transgênicas foram aprovadas e comercializadas no mundo, como: o milho, a soja e o algodão, frutas e verduras como o mamão-papaia, a berinjela e a batata (ISAAA, 2014, p 1). Também novas culturas foram aprovadas como a maçã que não escurece com o corte, 0 salmão o primeiro animal transgênico aprovado para consumo humano (CLIVE, 2015, p 4). Entre as aprovações, ressalta-se o primeiro eucalipto transgênico do mundo, liberado comercialmente (CLIVE, 2015, p 8).

No Brasil, conforme dados a Comissão Técnica Nacional de Biossegurança (CTNBio), foram aprovadas 11 variantes de soja transgênica, 40 de milho, 12 de algodão, 1 de feijão e 1 de eucalipto. Obteve-se aprovação para o cultivo de uma produção de $20 \%$ mais eucalipto, desenvolvido pela Futuragene/Suzano, além da comercialização de duas culturas em 2016 - um feijão resistente a vírus e uma nova soja tolerante a herbicidas (CLIVE, 2015, p 8).

Na América Latina, o Brasil se classificou em segundo lugar, cultivando na safra 2015/16 uma área de 44,2 milhões de hectares com culturas transgênicas, ficando atrás apenas dos EUA com 70,9 milhões de hectares. Em terceiro segue a Argentina, com uma área de 24,5 milhões, depois Índia (11,6 mi/ha), Canadá (11,0 mi/ha) e China (3,7 mi/ha). Em todo o mundo, 28 países plantaram 179,7 milhões de hectares com variedades geneticamente modificadas (CLIVE, BRIEF 51, 2015, p 2). Dos 28 países que plantaram culturas biotecnológicas em 2015, 87\% da área foi nas Américas, $11 \%$ na Ásia, 2\% na África e menos que 1\% na Europa (CLIVE, 2015, BRIEF 51, p 8). 
Em 2016, dezoito Organismos Geneticamente Modificados (OGMs) obtiveram liberação para produção comercial, dentre alimentos, microrganismos e vacinas (CTNBIO, 2016, p 3-5).

Segundo Adriana Bondrani, diretora-executiva do Conselho de Informações sobre Biotecnologia (CIB) "Dentre os países em que a biotecnologia está mais presente, o Brasil é o único que consegue expandir área sem avançar sobre áreas de preservação, por meio da recuperação de áreas degradadas" (CIB, 2016).

Desta forma, o crescimento do agronegócio de OGMs no Brasil é notório. Os transgênicos se consolidaram como a tecnologia agrícola mais rapidamente adotada na história recente da agricultura, ainda que a carência de pesquisas científicas seja uma realidade.

\section{BIOÉTICA E BIODIREITO NA QUESTÃO DOS QUESTÃO DOS ORGANISMOS GENETICAMENTE MODIFICADOS}

A bioética apresenta-se como uma manifestação de preocupação ética, especificamente relativa a progressos das ciências da vida. Revela a preocupação com o respeito à condição humana e do valor incondicional do próprio homem (SANTOS, 1998, p. 37).

Os avanços tecnológicos, principalmente em relação à biotecnologia, são temas que vêm despertando impactos positivos e negativos na opinião pública, demonstrando-se a necessidade de um monitoramento dos avanços nas referidas atividades.

O grande problema que cerne o assunto consiste na consequência do rompimento das barreiras da natureza. Seria viável? Seria perigoso? Seria controlável? As possíveis consequências maléficas podem ser revertidas? Essas e outras questões decorrentes do avanço ao desconhecido são objeto importante de discussão científica e social para o crescimento sustentável.

O cume da questão quanto aos OGMs está pautada na imprevisibilidade e irreversibilidade. A produção comercial já está sendo realizada, mas, tecnicamente, não se sabe quais serão as adversidades provenientes deste feito e a possibilidade de suas remedições.

Quanto aos riscos, é certo que toda ação implica uma reação, sendo impossível se promover uma inovação biotecnológica sem esperar riscos decorrentes da 
atividade. Neste contexto, cabe a sociedade em geral e a sociedade científica apurar qual seria a melhor posição ética, frente aos riscos esperados ou não da produção transgênica, pois, se por um lado esta representa competitividade e evolução, por outro pode representar o fim de espécies animais e vegetais, uma ameaça à saúde humana e ao meio ambiente e a convivência pacífica entre este e aquele.

A bioética, representando a ética da vida, tem um importante papel na análise racional dos avanços tecnológicos em relação à segurança, baseada no princípio da precaução, bastante utilizado na discussão da liberação ou não de produção e comercialização de Organismos Geneticamente Modificados.

A bioética, neste contexto, tem por finalidade levantar questões, inquietações, possibilidade de erro e acerto, de benefício versus malefícios, em relação ao uso indiscriminado de práticas biotecnológicas, o qual poderá afetar a dignidade da pessoa humana. A bioética não visa decidir qual beneficência a geração atual quer para si ou para as futuras gerações, apenas levantar questões (HIRONAKA, 2003, p. 42).

Assim como Moral e Direito, a Bioética e o Biodireito não se opõem, mas sim se complementam.

O Biodireito consiste num campo do conhecimento jurídico que toma como ponto de partida a bioética, porém, apresentando autonomia em relação a esta (GAMA, 2003, p.37). Amaral (apud HIRONAKA, 2003, p. 47) define o Biodireito como "o conjunto de valores, princípios e normas que tem por finalidade proteger a vida humana, disciplinando a prática de suas intervenções e os mecanismos de sua manipulação".

Dentro desta definição de biodireito, o papel do direito seria de sistema de resolução de conflitos ou de preservação de direitos.

Conforme já aludido, questões decorrentes do avanço tecnológico não são apenas objeto de preocupação da bioética, devendo existir determinadas regras comportamentais dotadas de obrigatoriedade, generalidade, coercibilidade e imperatividade, gerando normas jurídicas e construindo o biodireito (GAMA,2003, p.105).

O biodireito não tem por objetivo cercear o desenvolvimento científico, mas sim traçar exigências mínimas que assegurem o desenvolvimento tecnológico, respeitando-se os valores da sociedade. 
É notória a correlação entre a bioética e o biodireito, pois as suscitações da primeira extravasam sua esfera e inundam a dimensão jurídica. Enquanto a bioética apresenta novas situações da vida da sociedade, novos conhecimentos e rompimentos de paradigmas, fatores que necessitam da atenção do legislador, para impor limites legais e garantir dos padrões de dignidade e ética (HIRONAKA, 2003, p. 46).

Desta forma, a questão do desenvolvimento sustentável depende tanto do conhecimento científico, como da incessante persecução dos técnicos das ciências jurídicas, de modo que o avanço tecnológico seja pautado na segurança e preservação de ambiente saudável.

\section{DESENVOLVIMENTO SUSTENTÁVEL E A COSMOVISÃO ANTROPOCÊNTRICA}

A ideia do desenvolvimento sustentável consiste em atender as necessidades do presente sem comprometer as necessidades das futuras gerações.

No Brasil, o marco referente ao desenvolvimento sustentável ocorreu com a Conferência das Nações Unidas sobre Meio Ambiente e Desenvolvimento - Rio 92, a qual demonstrou a possibilidade de desenvolvimento sustentável a partir congregação entre o princípio da preservação e desenvolvimento econômico.

Tanto o entendimento de desenvolvimento sustentável quanto o artigo 225 da Constituição Federal da República do Brasil de 1988 apresentam uma visão antropocêntrica, pois, preconizam que o meio ambiente deva ser preservado em função do homem, colocando este como espécie dominante.

O Antropocentrismo, proveniente da Filosofia, consiste num pensamento ou organização o centro do Universo e que ao redor dele existem os demais serem em posição subalterna e condicionada. Nesta concepção, o homem seria o eixo de um determinado sistema (MILARÉ; COIMBRA, 2004).

A implantação do desenvolvimento sustentável é considerada um tanto utópica, uma vez que a ideia de globalização e interesse econômico vem tornando inviável a aplicação de um modelo economicamente sustentável (FIGUEIREDO; RODRIGUES, 2002, p.262 apud PHILIPPI; RODRIGUES, 2005, p. 8).

A incompletude legislativa e morosidade no acompanhamento dos avanços tecnológicos geram ao cidadão insegurança, ao passo que não possui critérios claros e objetivos que possam apoiar confiadamente sua conduta. 


\section{RISCOS, INCERTEZAS E FALHAS NA PRODUÇÃO DE TRANSGÊNICOS}

A polêmica sobre transgênicos certamente decorre da falta de informações completas e confiáveis quantos aos riscos, benefícios e limitações.

A produção científica brasileira sobre o assunto é deficiente. Segundo estudo realizado em 2009 (CAMARA, 2009, p 678), produção científica é escassa e justifica a polêmica sobre o tema, não obstante, questiona em quais estudos a CTNBio se baseou permitir a produção comercial de transgênicos se os estudos analisados na amostragem que discursam sobre insegurança alimentar afirmam que tais alimentos não são seguros.

Não obstante, a própria Lei de Biossegurança é falha, ainda que venha passando por vários processos de regularização. A primeira crítica que se faz à Lei de Biossegurança está na miscelânea de temas a que esta trata; matérias que deveriam ser abordadas em normas distintas, ou seja: pesquisa e fiscalização de OGMs, utilização de células-tronco embrionárias para fins de pesquisa e terapia, estrutura e competências da CTNBio e ainda criação e organização do Conselho Nacional de Biossegurança. Ainda, mais crucial nesta questão é tratar de plantas e produtos (OGMs) e da saúde humana num mesmo contexto de lei.

Em segundo lugar destaca-se que a linguagem legislativa é ambígua e confusa, pois a lei define termos técnicos já definidos pela biologia e que não sofreram alterações, como por exemplo: ADN e RDN (MARTINS-COSTA; FERNANDES; GOLDIM, 2005).

Em seu artigo primeiro, a Lei 11.105/05 aponta o como princípio norteador o "princípio da precaução", entretanto, não cabe à lei pautar-se diretamente em princípios, incumbindo à jurisprudência e à doutrina esta tarefa com o propósito de suprir eventuais deficiências da lei. Ademais, destaca-se o princípio, mas não indica critérios de concretização do mesmo.

Outra falha da Lei de Biossegurança persiste na possibilidade da CTNBio poder ou não exigir a realização do estudo prévio de impacto ambiental e seu respectivo relatório (EIA/Rima), se entender necessário, estando esta discricionariedade prevista também em nossa carta constitucional (artigo 225, parágrafo $1^{\circ}$ ).

Em contraposição, Walter Colli (COLLI, 2011, p 148-173) acredita que a Lei de Biossegurança é excessiva, apoia racionalidade no debate e começa a desregular o que está regulado em demasia. Segundo o autor, tanto no exterior como no Brasil, 
nos últimos quinze anos nunca evidenciaram, nos produtos liberados, efeitos adversos à saúde humana e animal ou ao ambiente. Afirma que o excesso de regulamentação favorece as grandes empresas que têm recursos e tempo para atender a todas as demandas regulatórias e que as pequenas empresas ou estatais como a Embrapa não têm orçamento para cumprir os exageros do excesso de regulamentação.

Um tema bem atual é a discussão sobre a importância da rotulagem dos alimentos, importante para auxiliar o consumidor a fazer escolhas alimentares apropriadas, devendo apresentar identificação da composição de forma autêntico, clara e completa.

No tocante à rotulagem, o artigo 40 da lei de biossegurança prevê a necessidade de identificação do produto transgênico. Entretanto, apesar da vasta legislação a respeito, a fiscalização no Brasil é muito deficiente, proporcionado a insegurança alimentar. Estudos apontam irregularidades na rotulagem da transgenia nos produtos. Falta informação na lista de ingredientes, falta de destaque no símbolo, assim como o termo da transgenia no painel principal do rótulo (GINANI, 2013, p 415431).

O $\S 1^{\circ}$ do artigo $2^{\circ}$ do Decreto n. 4.680, de 24.4.2003 estabeleceu que juntamente com as expressões, também deve constar no rótulo o símbolo transgênico definido pelo Ministério da Justiça na Portaria n. 2.658/2003, representado por um triângulo equilátero com a letra "T" no centro, com bordas e letra pretas e fundo amarelo, podendo também ser impresso em preto e branco.

Além de falhas na rotulação de produtos, pesquisas realizadas diretamente com consumidores indicam que, ainda que haja rotulação do transgênico, o ônus recai sobre o consumidor individual, pois, além do consumidor ter pouco tempo para realizar compras e não ler rótulos, ainda existe a deficiência no grau de escolaridade para ler e entender rótulos, assim como as informações ali contidas não são compreensíveis, idôneas, claras e adequadas. (FURNIVAL, 2009, p. 01-19).

Segundo o site da BBC Brasil, já estão inseridos na cadeia alimentar os seguintes produtos: milho com seus derivados e subprodutos como glucose e amido e, por consequência salgadinhos, bolos, doces, biscoitos, sobremesas); a soja e seus derivados (leite de soja, tofu, bebidas de frutas e soja); óleos extraídos de soja, milho e algodão; feijão resistente ao vírus do mosaico dourado.

O direito à informação guarda correspondência direta com outros resguardados pela Constituição Federal: saúde, alimentação, ambiente ecologicamente equilibrado, 
e incumbe, assim, o Poder Público controlar a produção, a comercialização e o emprego de técnicas, métodos e substâncias que comportem risco a saúde humana e ao meio ambiente.

Em investigação realizada pelo Centro de Pesquisas Pew, em relação a visões dos cientistas junto com a Associação American a para o Avanço da Ciência (AAAS) e o público em geral, demonstrou que há uma lacuna significativa entre crenças do público e dos cientistas sobre as ciências Biomédicas. Apurou que mais da metade do público em geral (57\%) diz que os alimentos GM são arriscados para o consumo. Entretanto, a maioria (88\%) dos cientistas da AAAS diz que os alimentos GM são geralmente seguros (Pew Research Center, 2015).

A participação da sociedade é fundamental neste processo conhecimento e de conscientização, para a livre escolha e consumo consciente, uma vez que o direito à informação contribui à interação mais respeitosa do homem com o ambiente e implementação do Estado Socioambiental de Direito (SILVA, 2015, p. 103-120).

\section{CONSIDERAÇÕES FINAIS}

Com o progresso científico, surgiu uma reação da bioética e do biodireito, fazendo-se necessário conservar o respeito à dignidade humana, a fim de que os avanços científicos não superem a importância do próprio homem.

A bioética e o biodireito estão inseridos nas conquistas do homem, devendo mediar uma perfeita harmonia entre tecnologia e a preservação de todas as espécies.

Neste contexto, o direito empenha um papel fundamental na busca do bem comum, através de regras de conduta, a fim de direcionar comportamentos e aplicar sanções àqueles que infringem a lei. Quanto à temática referente ao meio ambiente, o Estado tem o papel de tutor deste patrimônio comum a todos os seres.

Considerando o reduzido conhecimento científico e divergentes estudos a respeito dos riscos dos transgênicos, e, tratando-se de uma nova tecnologia, é extremamente necessária uma análise criteriosa quanto à autorização comercial dos alimentos transgênicos em relação ao plantio e consumo em larga escala. Para referida análise, é indispensável à realização de estudo de impacto ambiental, com todo rigor.

Havendo ausência de evidências científicas quanto à ameaça à biodiversidade ou à saúde humana, não pode a deficiência ser utilizada como um favorecimento para 
se definir um jogo tão arriscado e talvez sem volta, devendo ser levadas em consideração todas as hipóteses a favor ou contra, ou ainda as incertezas. Neste sentido, afirma Traavik (1999 apud GUERRA; NODARI, 2003, p.65): "ausência de evidência jamais deve ser tomada como evidência da ausência”.

Importa salientar que não se pretende com o presente trabalho se posicionar contra a atividade envolvendo OGMs, mas sim levantar as incertezas, os problemas que comprovadamente já existem e os que ainda não foram estudados ou comprovados em relação aos riscos.

A questão dos OGMs, sua produção, sua liberação para o consumo, depende muito mais da segurança das pesquisas científicas do que propriamente do direito, pois, a Lei de Biossegurança foi criada para mediar o problema da necessidade do avanço tecnológico e o temor de uma liberação desregrada dos alimentos sem fiscalização da atividade ou punição para seus infratores.

Entretanto, construção de um sistema de regulação e normatização em biossegurança é um desafio e deve ser feito de forma multidisciplinar, pois a aceitação e real implementação dependem da confiança pública (CAMARA, 2012). Também é necessário o aprimoramento dos setores de fiscalização governamental, pois, a Lei de Biossegurança deixa a encargo daqueles a autorização para o plantio com base nas diretrizes do Conselho Nacional de Biossegurança, de acordo com a conveniência e oportunidade sócio-econômica.

Considerando as mudanças climáticas, todas as tecnologias, são indispensáveis para o futuro da humanidade. O grande problema não está no desenvolvimento de novas tecnologias, mas sim na falta de segurança científica, usos inadequados e consequência destes no contexto socioambiental.

Segundo o cientista Hugo de Vries (1907) "Numa ciência aplicada como a genética agrícola, o econômico domina o científico e, além dos ganhos financeiros, determina o que é cientificamente verdadeiro" (apud ODARI, 2016). Neste contexto, não se pode deixar que interesses socioeconômicos suplantem a segurança do meio ambiente e saúde dos seres vivos. A solução está pautada na remodelação de políticas públicas de modo que garantam o desenvolvimento seguro, preservando o meio ambiente para futuras gerações.

O desenvolvimento sustentável no Brasil somente terá sua efetividade se ponderados os fatores econômicos e preservados os recursos naturais pois, se primar 
precipitadamente pelo interesse econômico, poderá se perder o bem maior que garante a sobrevivência humana no planeta.

Em suma, apesar da importância econômica da produção de Organismos Geneticamente Modificados, é necessário primar pela segurança da saúde, alimentar e do meio ambiente através de investimentos em pesquisas científicas e controle de produção e comercialização de produtos por órgãos públicos através de rígidos protocolos de biossegurança. Por questão de proteção, os interesses naturais devem ser primados enquanto existirem incertezas científicas em relação as suas vantagens e ausência de riscos da produção transgênica. Nesta esteia, é relevante a adoção do princípio da precaução para evitar a irreversibilidade e o princípio do desenvolvimento sustentável para garantir a satisfação das necessidades da sociedade atual e preservar os recursos naturais para futuras gerações. 


\title{
GENETICALLY MODIFIED ORGANISMS: THE LEGALIZATION IN BRAZIL AND SUSTAINABLE DEVELOPMENT
}

\begin{abstract}
This article analyses the legalization of transgenic food in Brazil in the face of risks and control mechanisms for production and commercialization of Genetically Modified Organisms (GMOs). The chosen method to do so is bibliographic research. The Biosafety Law, $\mathrm{n}^{\circ} 11.105$ of March 24, 2005, legalized the production of GMOs in Brazil, initially authorizing the genetically modified soybeans planting; since then, the law has been adapted to protect human health and environment safety. It will be analyses the shortcomings of scientific research to assess the safety issues regarding environment and consumers, as well as the receptivity of these genetically modified foods in the market. The Democratic State of Law is responsible for the environment protection and human health, therefore this article adopts the Bioethics and Biolaw perspectives. In summary, it is presented problems related to the insufficiency of scientific research regarding the production of GMOs and food security, the exposure risks of irreversible damage to the environment and to human beings, economic necessity and protection of the State in compliance with sustainable development.
\end{abstract}

Keywords: Transgenic. Biosafety. GMOs. Sustainable. Development.

\section{ORGANISMOS MODIFICADOS GENÉTICAMENTE: LA LEGALIZACIÓN EN BRASIL Y EL DESARROLLO SOSTENIBLE}

\section{Resumen}

Análisis de la legalización de los alimentos transgénicos en Brasil, los riesgos y mecanismos de control para la producción y comercialización de organismos modificados genéticamente (OMG). Por lo tanto, se realizó revisión de la literatura. La Ley de Bioseguridad № 11.105 de 24 de marzo de 2005, legalizó la producción de transgénicos en Brasil, autorizando inicialmente la siembra de soja transgénica; desde entonces, la norma ha sido adaptada a la necesidad de seguridad de la salud humana y del medio ambiente. Las deficiencias de la investigación científica para determinar la seguridad del medio ambiente y los consumidores, así como la receptividad de estos alimentos modificados genéticamente en el mercado va a ser tratado. Como el Estado Democrático de Derecho es responsable por la protección del medio ambiente y de la salud humana, se examinó el camino desde la perspectiva de la bioética y Bioderecho. En resumen, se discuten los problemas relacionados con la falta de investigación científica como la producción de organismos modificados genéticamente y la seguridad alimentaria, el riesgo de exposición del medio ambiente y el hombre el daño irreversible, la necesidad económica y la autoridad del Estado en cumplimiento de un desarrollo sostenible.

Palabras clave: Transgénicos. La bioseguridad. OMG. Desarrollo. Sostenible. 


\section{REFERÊNCIAS}

AUGUSTO, Lia Giraldo da Silva et al. As implicações socioambientais e econômicas do desenvolvimento agrário brasileiro modelo de produção agrária no Brasil. CARNEIRO, Fernando Ferreira et al (ORG.). Dossiê Abrasco: um alerta sobre os impactos dos agrotóxicos na saúde. Rio de Janeiro: EPSJV; São Paulo: Expressão Popular, 2015. parte 2.p. 96-107. Disponível em:

$<$ http://www.abrasco.org.br/dossieagrotoxicos/wpcontent/uploads/2013/10/DossieAbrasco 2015 web.pdf >. Acesso em: 07 mar. 2017.

AZEVEDO, Vasco. Transgenia para combater a dengue. 2016. Disponível em: $<$ http://cib.org.br/estudo/transgenia-para-combater-a-dengue >. Acesso em: $21 \mathrm{fev}$. 2017.

BRASIL. Lei $\mathbf{n}^{\circ}$ 11.105, de 24 de Março de 2005.Disponível em: <http://www.planalto.gov.br/ccivil 03/ Ato2004-2006/2005/lei/L11105.htm >. Acesso em: 14 fev 2017.

CAMARA, Maria Clara Coelho et al. Transgênicos: avaliação da possível (in) segurança alimentar através da produção científica. História, Ciências e Saúde Manguinhos: Rio de Janeiro, 2009. v. 16, n. 3, p. 678.

CAMARA, Maria Clara Coelho. Regulamentação e atuação do Governo e do Congresso Nacional sobre os alimentos transgênicos no Brasil: uma questão de (in)segurança alimentar. 2012. $100 \mathrm{f}$. Tese (Doutorado) - Escola Nacional de Saúde Pública Sergio Arouca, Rio de Janeiro, 2012. Cap. 3.

CIB - CONSELHO DE INFORMAÇÃO DE BIOTECNOLOGIA. 2016. Disponível em: < http://cib.org.br/brasil-lidera-crescimento-mundial-da-adocao-de-transgenicos/ >. Acesso em: 17 fev. 2017.

CLIVE, James. 20 ${ }^{\text {th }}$ Anniversary of the Global Commercialization of Biotech Crops (1996 to 2015) and Biotech Crop Highlights in 2015. Disponível em: $<$ http://cib.org.br/wp-content/uploads/2016/04/2016 0413 RelatoriolSAAA Eng.pdf Acesso em: 15 fev. 2016.

CLIVE, James at al. Invitational Essays to Celebrate the 20th Anniversary of the Commercialization of Biotech Crops (1996 to 2015): Progress and Promise.

BRIEF 51. 2015. Disponível em:

$<$ https://www.isaaa.org/resources/publications/briefs/51/essays/pdf/B51-EssaysEnglish.pdf >. Acesso em: 17 fev. 2017. 
COLLI, Walter. Organismos transgênicos no Brasil: regular ou desregular?

REVISTA USP, São Paulo, n.89, p. 148-173, março/maio 2011.

CTNBio - Relatório Anual 2016. Disponível em:

<http://ctnbio.mcti.gov.br/documents/566529/664456/Relat\%C3\%B3rio+Anual+2016/

9454371e-458e-46b6-b149-da50e4af4a08?version=1.0 >. Acesso em: 14 fev. 2017.

FIGUEIREDO, Guilherme José Purvin de; RODRIGUES, José Eduardo Ramos

Rodrigues. Do regime das reservas de desenvolvimento sustentável à luz do novo sistema nacional de unidades de conservação. In: FIGUEIREDO, G.J.P organizador. Desafios Éticos da Advocacia Pública. Rio de Janeiro: Esplanada, 2002, v. 1, p. 259-270.

FURNIVAL, Ariadne Chloe at al. O PÚBLICO E A COMPREENSÃO DA

INFORMAÇÃO NOS RÓTULOS DE ALIMENTOS: O CASO DOS TRANSGÊNICOS. Revista Digital de Biblioteconomia e Ciência da Informação, Campinas, v.7, n. 1, p. 01-19, jul./dez. 2009- ISSN: 1678-765X.

GAMA, Guilherme Calmon Nogueira da. O Biodireito e as Relações Parentais. Rio de Janeiro: Renovar, 2003.

GINANI, Janini; GOUVÊA, Heloisa Rodrigues de. Adequação da Rotulagem de Alimentos Transgênicos no Brasil baseada na legislação vigente. PUC-Goiás: $8^{a}$ MOSTRA DE PRODUÇÃO CIENTÍFICA DA PÓS-GRADUAÇÃO LATO SENSU DA PUC GOIÁS. ISSN: 2176-0705. 2013. P 415-431. Disponível em: <http://www.cpgls.pucgoias.edu.br/8mostra/Artigos/Caderno\%208\%20Mostra.pdf > Acesso em: 14 fev. 2017.

GUERRANTE, Rafaela Di Sabato. Transgênicos: uma visão estratégica. Rio de Janeiro: Interciência, 2003.

HIRONAKA, Giselda Maria Fernandes Novaes. Bioética e Biodireito: Revolução Biotecnológica, Perplexidade Humana e Prospectiva Jurídica Inquietante. In:

Revista Brasileira de Direito de Família. 2003, v.4, fasc. 16, p. 40-55.

ISAAA. Casos de dengue GM mosquitos reduzir em 91\% em Piracicaba, Brasil. 2016. Disponível em:

<http://www.isaaa.org/kc/cropbiotechupdate/article/default.asp?ID=14587 >. Acesso em: 21 fev. 2017.

KREUZER, Helen; MASSEY, Adrianne. Engenharia Genética e Biotecnologia. 2. 
ed. Porto Alegre: Artmed, 2002. 434p.

LEITE, Marcelo. Arautos da Razão: a paralisia no debate sobre transgênicos e meio ambiente. Novos Estudos. CEBRAP 78: julho, 2007. p. 47.

LOSEY, John E.; RAYOR, Linda S.; CARTER, Maureen E. Transgenic pollen harms monarch larvae. In: Nature, Londres, n.399, p.214, maio 1999. Disponível em:

$<$ http://www.nature.com/scitable/content/Transgenic-pollen-harms-monarch-larvae$\underline{9796}>$ >. Acesso em: 07 mar. 2017.

MARTINS-COSTA, Judith.; FERNANDES, Márcia Santana; GOLDIM, José Roberto. Lei de Biossegurança: Medusa Legislativa? Jornal da ADUFRGS. Maio 2005. p. 19:21. Disponível em: < https://www.ufrgs.br/bioetica/ibiosseg.htm >. Acesso em: 15 fev. 2017.

MILARÉ, Edis; COIMBRA, José de Ávila Aguiar. Antropocentrismo X Ecocentrismo na Ciência Jurídica. Revista de Direito Ambiental, ano V, $n^{\circ} 36$, outubro-dezembro 2004. São Paulo: Revista dos Tribunais, 2004. p.9-42. Disponível em: <http://www.egov.ufsc.br/portal/sites/default/files/anexos/26839-26841-1-PB.pdf >. Acesso em: 15 fev. 2017.

NODARI, Rubens Onofre; GUERRA, Miguel Pedro. Da Transformação de Bactérias às Plantas Transgênicas. In: Ciência \& Ambiente - Dna: 50 ANOS. Universidade Federal de Santa Maria - UFSM. Jan./jun. 2003. Semestral.

\section{NODARI, Rubens Onofre. O CENÁRIO DA PESQUISA CIENTÍFICA COM}

TRANSGÊNICOS. Florianópolis: Ufsc, 2016. 105 slides, color. Disponível em: $<$ http://www.mpf.mp.br/atuacao-tematica/ccr4/dados-daatuacao/eventos/Seminarios/Rubens.pdf >. Acesso em: 07 mar. 2017.

OXITEC. Dengue fever cases drop 91\% in neighbourhood of Piracicaba, Brazil, where Oxitec's Friendly ${ }^{\mathrm{TM}}$ Aedes were release. 2016. Disponível em:

$<$ http://www.oxitec.com/dengue-fever-cases-drop-91-percent-neighbourhoodpiracicaba-brazil-oxitecs-friendly-aedes-released/ >. Acesso em: 21 fev. 2017.

PEW RESEARCH CENTER. Public and Scientists Express Strikingly Different Views about Science-Related Issues . 2015. Disponível em:

$<$ http://www.pewinternet.org/2015/01/29/public-and-scientists-express-strikinglydifferent-views-about-science-related-issues/ >. Acesso em: 21 fev. 2017. 
RODRIGUES, Maria Rafaela Junqueira Bruno. Biodireito: Alimentos Transgênicos. São Paulo: Lemos \& Cruz, 2003.

SANTOS, Maria Celeste Cordeiro dos. O Equilíbrio do Pêndulo - A Bioética e a Lei: Implicações médico legais. São Paulo: İcone, 1998.

SILVA, Brisa Arnoud da. A Sociedade da Informação a Favor da Democracia: o Direito da Informação e Livre Escolha no Consumo De Alimentos Transgênicos. Ponta Grossa: Publicatio UEPG - Ciências Sociais aplicadas, 2015. p. 103-120. Disponível em:

<http://www.revistas2.uepg.br/index.php/sociais/article/view/7158/4623 >. Acesso em: 14 fev. 2017. 